\title{
Dietary Intake and Nutritional Anthropometry of the Workers of INDAL, Hirakud
}

\author{
Braja Kishori Mishra and Swapna Mohanty \\ Department of Home Sciences, Sambalpur University, Jyoti Vihar 768019, \\ Sambalpur, Orissa, India
}

KEYWORDS Food and Nutrient Intake. Nutritional Status. Body Mass Index. Weight for Height. Writh's Standard

\begin{abstract}
The present survey was carried out to record the food and nutrient intake from the industry run canteen by the employees of INDAL, Hirakud. An attempt has also been made to record the nutritional status of the employees through nutritional anthropometry with an intention to observe the consequences of the dietary intake. It was observed that the consumption of all most all the food- stuffs except cereals, milk, and nuts and oilseeds was more than the RDA. Similarly the consumption of all the three principal nutrients i.e carbohydrate, protein and fat was also recorded to be very high, which provides a lot of calories to the diet. When the ideal weight was calculated as per the Broca Index and then the percentage of weight was classified, (Waterlow's classification) $46.14 \%$ were recorded to be normal whereas $37.2 \%$ were undernourished and $16.6 \%$ were obese. The Writh's standard was taken into consideration for the calculation of percentage of weight deficit or excess. $57.25 \%$ were recorded to be normal and $31.4 \%$ undernourished and only $11.35 \%$ were observed to be obese. The prevalence rate of undernutrition varie from $6.5 \%$ to $31.4 \%$, in the different indices used, where as prevalence rate of over nutrition varies from $11.35 \%$ to $19.56 \%$. Low educated and low income group employees constitute the major proportion $(58.66 \%$ and $56 \%)$ of the over nourished employees.
\end{abstract}

\section{INTRODUCTION}

The recent few decades have witnessed phenomenal industrial progress among the developing countries, including India. Several of these industries have large-scale employment potential. Industrial workers constitute a vital segment in view of their significant contribution to the national income (WHO 1978). Rapid industrialization has resulted in the increase in number of persons seeking gainful employment. Working efficiency and output are very much dependant on the health and physical fitness of the individual. Provision of nutritionally adequate diet for the workers was quickly appreciated not only as an important forward step in social practice but also for increasing industrial efficiency. Nutrition not only plays an important role in the efficiency and welfare of the workers, but also adequate diets are essential for optimum output. Further organized feeding programmes for industrial workers in public sector undertakings is gaining importance to promote better nutritional

Address for correspondence:

Braja Kishori Mishra

Professor and Head

Department of Home Sciences, Sambalpur University, Jyoti Vihar-768 019, Orissa

Fax:0663-2542301,E.-mail:bkm_su@ @rediffmail.com status, since well fed labour force and productivity are closely related (Swaminathan 1967).

There have been several country-wide Diet and Nutrition Surveys in India. But few of these pertain to industrial workers and cover such aspects as common nutritional disorders and dietary intake (De Mello et al. 1950; Banerjee et al. 1959; Ramanamurthy and Dakshayani 1962; Swaminathan 1967; Sharan and Puttaraj 2003) and work output (Satyanarayana et al. 1972, 1977, 1979). Thus more attention needs to be given to obtain data on the physical and nutritional status of different categories of workers in different income groups, their knowledge and practices regarding health and nutrition. This enables formulation of sound and effective nutrition education action programmes for promoting workers health and nutritional status.

In this backdrop, the present survey was carried out to record the food and nutrient intake from the industry run canteen by the employees of INDAL, Hirakud. There is a canteen in the factory, which supplies tea, breakfast, lunch and dinner to the employees of the factory free of cost. Though all the employees are not forced to take food in the canteen but a large majority takes the food supplied by the canteen. According to the working hours of the factory one employee is supposed to take half day's meal i.e. either 
breakfast and lunch or afternoon snacks and dinner. Besides this, an attempt has also been made to observe the present nutritional status of the employees through nutritional anthropometry, to observe the consequences of the dietary intake.

\section{METHODOLOGY}

The survey was carried out during 2002-03 among the industrial workers of INDAL smelter. The data analyzed consist of the quantity and quality of food provided by the factory to the workers and the anthropometric measurements recorded from the 414 numbers of workers selected randomly from 860 workers. The workers who used to take foods regularly for more than 3years in the factory canteen were selected as the sample for obtaining the anthropometric information. The main objective was to observe the quality and quantity of food supplied by the industrial canteen, as the canteen supplies the foods to the workers free of cost. The canteen has the provisions of serving breakfast, lunch, dinner, tea and snacks, all through the day, to cater to the needs of 860 employees. The seven days food measurement method (Park and Park 1991) was followed to estimate the mean intake (Per Capita) consumption of the raw food by the employees from the canteen. All the raw food stuff used in the canteen before the preparation of different dishes were measured and recorded under the food groups like, cereals, pulses, green leafy vegetables, other vegetables, roots and tubers, fats and oils, fleshy foods, milk and milk products and sugar and jaggery . The nutrient content of each food item was estimated following Gopalan et al. (1991). The average quantity of consumption of each of these major food groups and nutrient groups for a worker for a day was estimated and compared with the quantity of Recommended Dietary Allowance for the Indians by ICMR (1984). The dietary and nutrient intake is expressed as percentages of the excess/deficit of the Recommended Dietary Allowances for Indians (ICMR 1984). The limitation of the study is that, the loss through damage and wastage was not taken into consideration in the calculation and it was assumed that all category of employees consumed approximately equal amounts of food.

A personal interview schedule was also designed, pre-tested and refined for the collection of general information and family information from a sample of 414 employees selected randomly from among 860 employees. Information on dietary habit and practices, health condition of the employees, the type of treatment followed during illness, and any restriction on the intake of foods was also taken in to consideration for the analysis of the data. To asses the nutritional status of the employees, height and weight, the two commonly used anthropometrical measurements were recorded, (Jelliffe 1966). Few anthropometrical indices like Body Mass Index (Rao et al 1986; Paul Deurenberg 1991) and weight for height taking Broca index and Writh's standard were also calculated to asses the nutritional status of the employees (Park and Park 1991).

\section{RESULTS AND DISCUSSION}

\section{Food and Nutrient Intake}

Dietary studies have been widely used, by several workers, to estimate the total calorie intake in terms of carbohydrate, fat and protein. The assessment of nutritional status from foodintake survey is important for determination of caloric balance in a group of population. For the present study, the seven days food measurement method (Park and Park, 1991) was followed for the diet survey. Only the canteen foods were taken into consideration. Per capita consumption of different food items per half-a-day was estimated (from the foodstuff issued from store) and compared with half-day recommended dietary allowances (RDA) of ICMR 1984. The calorific and nutritive values of different food- stuffs consumed by the employees were calculated using the tables of nutritive value of Indian food (Gopalan et al., 1991). The dietary and nutrient intake is expressed as percentages of the excess/ deficit of the Recommended Dietary Allowances for Indians (ICMR 1984).

\section{Dietary Intake}

Table 1 shows the mean per capita half-day consumption of different food items from the canteen by the employees of INDAL against the half day's quantity recommended and its deviance in percent to RDA. These intakes were compared with the quantity of dietary allowances recommended (NIN); for the three different working groups.

Cereals: The average intake of cereals from the canteen was estimated to be $181.9 \mathrm{gm}$ by the 

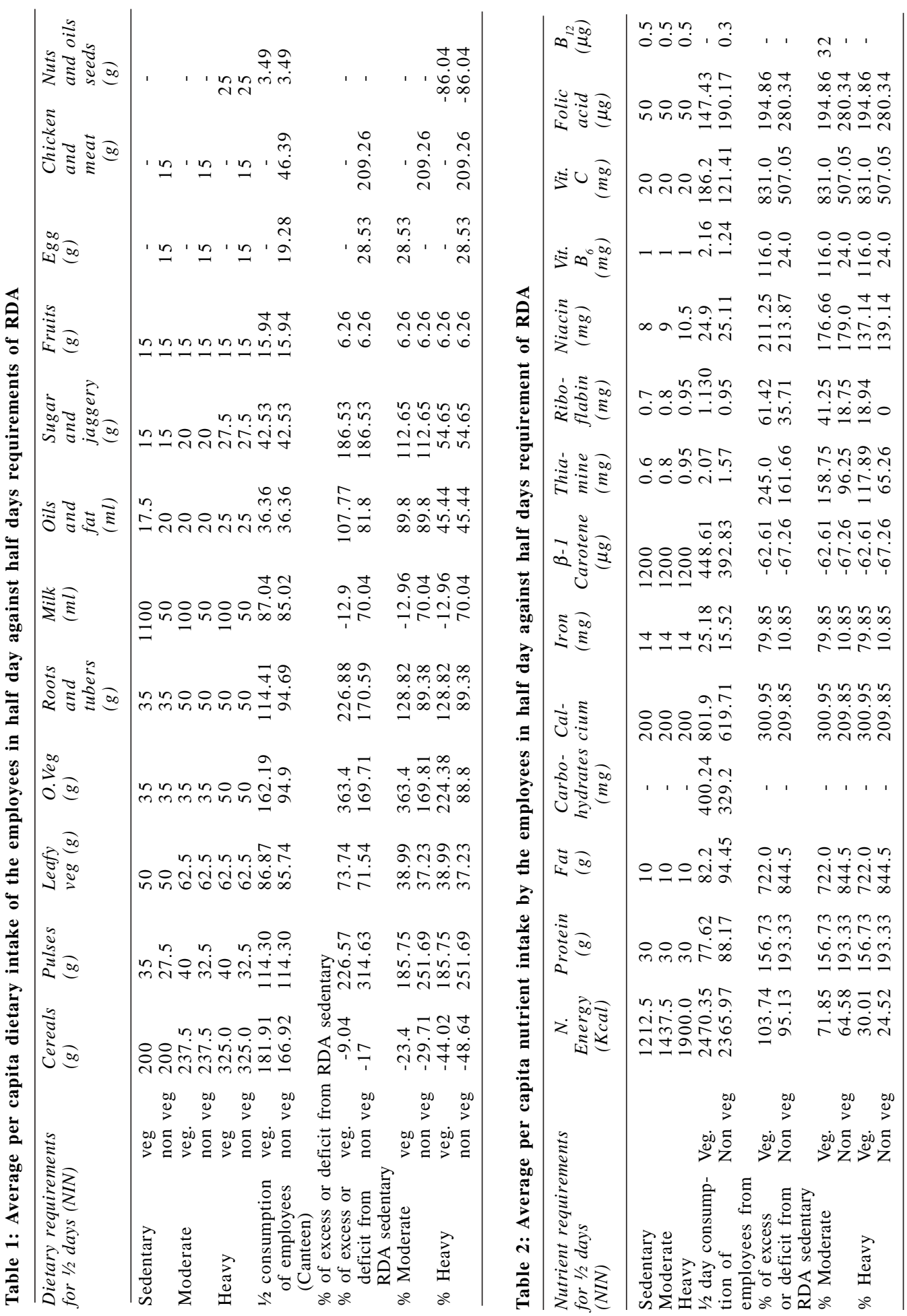
vegetarians and $166.9 \mathrm{gm}$ by the non-vegetarian. It was found that the cereal intake was deficit by $9.04 \%$ in case of sedentary vegetarians to $48.64 \%$ in heavy working non vegetations (Table-1). In all the categories the cereal intake was found out to be less, but when other food groups were taken into consideration, this deficit was found to be negligible as the intake of other energy giving foods like roots and tubers and other vegetables are found out to be in excess of the recommended allowances.

Pulses: The mean intake of pulses in half day by the employees in the canteen was $114.3 \mathrm{gm}$ in both vegetarian and non-vegetarian groups. This quantity consumption was found to be very high in comparison to the RDA. It is $226.57 \%$ to $315.63 \%$ excess incase of sedentary workers, $185.75 \%$ to $251.69 \%$ excess in case of both moderate and heavy workers . Pulses are rich in protein and also supply energy equivalent to carbohydrates. The excess Intake of protein than the required is always converted to fat and deposited in the body.

Leafy Vegetables and Other Vegetables: The average consumption of leafy vegetables from the canteen was $162.1 \mathrm{gm}$ by the vegetarians and $94,4 \mathrm{gm}$ by the non-vegetarians, and the quantities were approximately $37.23 \%$ (in case of sedentary vegetarians) excess of the requirements . Similarly, the intake of other vegetables was also found to be excess in the range of $88.8 \%$ to $363.4 \%$ (from sedentary to heavy worker). Leafy vegetables and other vegetables are always considered as protective and regulatory foods. The supply of vitamins, minerals and fibers from these are important. Though the intake was recorded more than the required, it is not possible to conclude that the supply of vitamins and minerals is excess, because during the handling and processing larger quantities of vitamins and minerals are generally lost. Moreover the water- soluble vitamins and minerals are excreted from the body through urine.

Roots and Tubers: The mean intake of roots and tubers by the employees from the canteen in half-day was $94.69 \mathrm{gm}$ by non-vegetarian and $114.4 \mathrm{gm}$ by vegetarians. It was excess by $89.38 \%$ in case of non-vegetarian heavy and moderate workers to $226.88 \%$ excess incase of sedentary vegetarian workers. Roots and Tubers are always responsible to increase the calorie content of the foods and excess calorie intake than the requirements are always deposited in the form of lipids in the adipose tissues of the body. It has been observed and mentioned above that the cereal intake of the workers was less than the RDA, which may be compensated to some extent by this excess intake of roots and tubers. But the intake was more than $200 \%$ excess in case of sedentary workers, which may lead to some problem if this practice is continued for a long period.

Milk: The average intake of milk was $87.04 \mathrm{~m} 1$ to $85.02 \mathrm{~m} 1$ in case of vegetarian and non.-vegetarian respectively. Milk consumption was found to be deficient in case of vegetarian employees. As milk supplies protein, the intake of milk should be more among the vegetarians. Maximum consumption of milk by the employees is in the form of tea. For most of the nonvegetarians the milk consumption was excess by $10.04 \%$. The other source of protein i.e. pulses intake was also recorded to be very high. Thus the deficit of milk does not adversely affect the qualities of the diet very much.

Oils and Fats: The average consumption of oils and fats by the employees was $36.36 \mathrm{ml}$ per half day. Oils and fats are the concentrated source of energy. The excess intake of oils and fats, gets deposited in the body in the adipose tissues, and makes the person either overweight or obese, which is again responsible to make a person susceptible to many diseases. Excess consumption of fats and oils recorded in the present study was in the order of $107.77 \%$ among sedentary vegetarian workers, $81.8 \%$ among moderate workers and $45.4 \%$ among heavy workers. The practice of frying most of the vegetables is mainly responsible for the observed excess intake.

Sugar and Jaggery: The average intake of $42.53 \mathrm{gm}$ of sugar was recorded for the employees. Most of this sugar consumption was in the form of tea. Sugar is the source of readily available calories. The consumption of sugar was also recorded very high i.e $183.5 \%$ excess among sedentary workers, $112.65 \%$ among moderate workers and $54.65 \%$ among heavy workers . Reduction in the consumption of this sugar is very much essential to reduce the calories content of the foods.

Fruits: The mean intake of fruits by the employees was $15.9 \mathrm{gm}$ per half-day from the canteen, which was approximately $6.26 \%$ excess than the recommended. Compared to other food items the excess intake of fruits is negligible.

Egg, Chicken and Meat: The average in- 
take of egg was $19.28 \mathrm{gm}$ and that of chicken and meat was $46.39 \mathrm{gm}$., which were $28.53 \%$ and $209.26 \%$ excess than the recommended respectively. As in the canteen only half-day's intake was recorded and if we assume that the nonvegetarian employees don't take chicken and meat in their meals at home then also the observed intake was $54.63 \%$ excess of the RDA

Nuts and Oilseeds: The intake of nuts and oilseeds was negligible i.e. $3.49 \mathrm{gm}$ by the employees in the canteen. Nuts and oilseeds are prescribed for the heavy workers only to compensate the extra calorie requirements by them. Though in this case the intake was less but the intake of oil and fats, sugar, roots and tubers were higher enough to fulfill the higher calorie requirement.

\section{Nutrient Intake}

Table 2 shows the recommended per capita daily nutrient intake for the different categories of workers on the basis of their working conditions Their per-capita half-day consumption at the canteen was shown against the half-day's Recommended Dietary Allowance (percentage of excess or deficit).

Energy (in Kcal): The calorie intake was recorded to be higher in all the three categories of employees i.e. sedentary worker, moderate workers and heavy workers. In case of the heavy workers the excess was in between $24.52 \%$ to $30.01 \%$ where as in case of sedentary workers it was $95.13 \%$ to $103.74 \%$ more.

Protein: The requirement of protein as per the RDA is $30 \mathrm{gm}$ per half day per adult. But the consumption of protein per half-day by the employees of the INDAL was recorded to be $77.62 \mathrm{gm}$ in case of vegetarians and $88.17 \mathrm{gm}$ in case of non-vegetarians. It is interesting to record that the consumption of protein was $156.73 \%$ excess in case of vegetarians and $193.33 \%$ excess in case of non-vegetarians irrespective of the working categories.

Fat: The average consumption of fat in halfday from the canteen by the employees was $82.20 \mathrm{gm}$ in case of vegetarian and $94.45 \mathrm{gm}$ in case of non-vegetarian which was $722.0 \%$ and $844.5 \%$ excess than the requirement (RDA) in vegetarian and non-vegetarian respectively (Table 2). The intake of fat was extremely high than the other nutrients, which needs to be reduced, other wise prolonged intake of this amount of lipids by the employees may lead to abnormalities.

Minerals: The consumption of Iron and calcium was taken into consideration and the intake of these minerals was excess in the employees, who take their food from the canteen. $209.85 \%$ to $300.95 \%$ excess consumption of calcium and $10.85 \%$ to $79.85 \%$ excess consumption of Iron were recorded in case of non vegetarian to vegetarian employees because of the inclusion of foods, which are rich in iron and calcium (Table 2). As the survey was conducted in winter, a good quantity of cabbage was included in the diet, which is a rich source of calcium. Everyday consumption of Idli containing black gram dhal contributes to high calcium intake. The consumption of green peas and beans during winter also contributes to high iron content of the diet.

Vitamins: Excepting the intake of carotene and Vitamin $\mathrm{B}_{12}$, all other vitamins (Thiamin, riboflavin, Niacin, vitamin B, Vitamin C, Folic acid) intake was recorded to be excess than the requirement. The intake of carotene was deficit by $62.6 \%$ to $67.26 \%$ and the intake of Vitamin $B_{12}$ was deficit by $32.0 \%$ (Table 2). As the loss of the vitamins, through processing and preparation of the foods and loss through wastage was not taken into consideration, the excess intake of these water soluble vitamins is always subject to criticism and it is not possible to analyze the exact amount of vitamins present in the foods after it was processed and prepared. It was observed that the consumption of all most all the foodstuffs excepting cereals, milk, and nuts and oilseeds was excess than the RDA. Similarly the consumption of all the three principal nutrients i.e. carbohydrate, protein and fat was also recorded to be very high, which provides a lot of calories to the diet. In this connection, it must be mentioned that, the consumption from the canteen accounts for only half of the day. The consumption in the other half of the day by the employees (in their homes) was not taken into consideration. So if the intake in the other half of the day is of lower in quality and quantities then it may possible to have a balance in calorie intake. But if the intake in the other part of the day is similar with that of the canteen, then it will definitely show its effect in the long run.

In this connection, it is essential to mention that, the estimation was based on 7 days average consumption of raw foods. Wastages during processing and cooking of the foods and as 
well as wastage of the cooked foods (left-over) are not taken into consideration. In spite of all this the intake were recorded to be higher than the RDA and thus it is essential to reduce the consumption of pulses and fats to some extent, Besides, the practice of frying all the vegetables and other food- stuffs should be minimized to reduce the consumption of oil. The intake of roots and tubers should also be curtailed, as it unnecessarily increases the calories consumption. The consumption of milk was found to be deficit among vegetarian therefore, it is essential to increase the amount of fresh curds in the meals to overcome the deficit of milk. Vegetables rich in carotene like carrot, Red gram dal, amarantha, and other leaves and like Drumstick leaves, fenugreek leaves coriander leaves should be included in the diet to compensate the deficit of carotene in the diet.

\section{Nutritional Anthropometry}

Change in growth is not only an important and objective manifestation of malnutrition, but also the first response to nutritional deprivation or excess. Measurement of growth, therefore, for long has been considered as a valuable tool for the assessment of nutritional status, Obesity or excess fatness is the commonest problem of the affluent and is the nightmare of middle aged man. The prevalence of obesity in our country is high enough to make it a serious health problem. In strict terms, the diagnosis of this disorder depends on the demonstration of an increased body-fat content. However, nutritional anthropometry is also commonly used to diagnose the obesity. An excess of $20 \%$ above the ideal body weight can be termed as obesity. Different types of nutritional indices are also used to measure obesity in adults.

In case of the workers of the INDAL, the dietary survey of the foods supplied by the canteen shows that the intake of calorie, protein and fat, and majority of the vitamin and mineral was recorded to be higher than the recommended dietary allowances. Though $24 \sim 30 \%$ excess calorie intake was recorded in heavy workers, the intake of protein was recorded to be more than three times (156-193\% excess) and the intake of fat was recorded to be more than eight times (722$844 \%$ ) of RDA. In view of this, more calorie are obtained from this excess protein and fat than the requirement. This excess calorie intake will definitely lead to over-weight and obesity in the long run. But diet is not the only factor leading to obesity and over-weight. There are also other factors responsible for this. Thus an attempt has been made to assess the present nutritional status of the workers of INDAL to observe the consequences of this extra calorie intake and also the influence of socio-economic and other factors on the body size of the employees based on the sample survey of 414 employees.

Four different indices were used to assess the nutritional status of the employees. Body Mass Index (or BMI) calculated as weight / (Height $)^{2}$ is an age-independent index used popularly for assessment of nutritional status in all age groups. When the BMI of the employees was calculated $75 \%$ of employees were found to be normal, $18 \%$ obese and only $6.5 \%$ were suffering from different grades of under nutrition (Table 3).

Table 3: Prevalence rate of malnutrition according to BMI

\begin{tabular}{llrr}
\hline Grades of malnutrition & BMI Values & No. & $\%$ \\
\hline Grade III under nutrition & $(16)$ & 1 & 0.24 \\
Grade II under nutrition & $(16-17)$ & 3 & 0.72 \\
Grade I under nutrition & $(17-18.5)$ & 23 & 5.56 \\
Low weight normal & $(18.5-20)$ & 48 & 11.36 \\
Normal & $(20-25)$ & 265 & 64.01 \\
Obesity grade I & $(25-30)$ & 68 & 16.42 \\
Obesity grade-II & $(30)$ & 7 & 1.69 \\
\hline Total & & 414 & 100.00 \\
\hline
\end{tabular}

Body mass index $(\mathrm{BMI})=$ weight in $\mathrm{kg} /(\text { height in } \mathrm{mt})^{2}$

Weight for height is also an age-independent index, and a good prognostic indicator of malnutrition. Ideal weight for height was estimated according to Wirth's Standard and then the percentage of weight for height was classified as per the Waterlow's classification. According to this classification $49 \%$ of employees were found to be normal, $31.41 \%$ undernourished and $19.56 \%$ obese (Table 4).

When the ideal weight was calculated as per the Broca Index and then the percentage of weight was classified, (Waterlow's classification) $46.14 \%$ were recorded to be normal whereas $37.2 \%$ were undernourished and $16.6 \%$ were obese (Table 5). The Writh's standard was taken into consideration for the calculation of percentage of weight deficit or excess and then it was classified as per Sarojini et a1. (1990). As per this $57.25 \%$ were recorded to be normal and $31.4 \%$ undernourished and only $11.35 \%$ were observed 
Table 4: Prevalence rate of malnutrition according to weight for height

\begin{tabular}{llrr}
\hline Grades of malnutrition & Values & No. & $\%$ \\
\hline Severely under nutrition & $<=75 \%$ & 13 & 3.14 \\
Moderate under nutrition & $>75-<=84 \%$ & 62 & 14.98 \\
Marginal under nutrition & $>84-<=90 \%$ & 55 & 13.29 \\
Normal & $>90-<=105 \%$ & 203 & 49.03 \\
Obesity grade I & $>105-<=115 \%$ & 59 & 14.25 \\
Obesity grade II & $>115 \%$ & 22 & 5.31 \\
\hline Total & & 414 & 100.00 \\
\hline
\end{tabular}

Wirth's standard: weight for Height: ideal weight in $\mathrm{kg}=$ ht. in $\mathrm{cm} \times 0.4$

(Waterlow's classification) percentage of weight for $\mathrm{Ht}$.

= Actual weight/ ideal weight X 100

Table 5: Prevalence rate of malnutrition according to weight for height

Grades of malnutrition Values No. $\%$

Severely under nutrition $<=75 \% \quad 20 \quad 4.83$

Moderate under nutrition $>75-<=84 \% \quad 59 \quad 14.25$

Marginal under nutrition $>84-<=90 \% \quad 75 \quad 18.12$

Normal

Obesity grade I >105-<=115\% $51 \quad 12.31$

$\begin{array}{llll}\text { Obesity grade-II } \quad>115 \% & 18 \quad 4.35\end{array}$

Total 414100.00

Broca Index $=$ Standard weight $=$ ht. in $\mathrm{cm}-100$

(Waterlow's classification) percentage of weight for $\mathrm{Ht}$ : $=$ actual weight $/$ standard weight X 100

to be obese (Table 6). The prevalence rate of under nutrition varies from $6,5 \%$ to 31.41 , in the different indices used, where as prevalence rate of over nutrition varies from $11.35 \%$ to $19.56 \%$.

To find out the probable cause of over nutrition, three parameters were identified, which have some contribution, either directly or indirectly towards over nutrition. These are education, per
Table 6: Prevalence rate of malnutrition according to Writh's standard

\begin{tabular}{|c|c|c|c|}
\hline $\begin{array}{l}\text { Grades of } \\
\text { malnutrition }\end{array}$ & Values & No. & $\%$ \\
\hline $\begin{array}{l}\text { Severely } \\
\text { under } \\
\text { nourished }\end{array}$ & $\begin{array}{l}\text { More than } 20 \% \text { less } \\
\text { than standard }\end{array}$ & 38 & 9.18 \\
\hline under weight & $\begin{array}{l}\text { Below } 10-20 \% \text { less } \\
\text { than standard }\end{array}$ & 92 & 22.22 \\
\hline Normal & $\begin{array}{l}\text { Below 0-10\% less } \\
\text { than standard }\end{array}$ & 237 & 57.25 \\
\hline Overweight & $\begin{array}{l}\text { Above } 10-20 \% \text { more } \\
\text { than standard }\end{array}$ & 37 & 8.93 \\
\hline Obese & $\begin{array}{l}\text { More than above } 20 \% \\
\text { of the standard }\end{array}$ & 10 & 2.42 \\
\hline
\end{tabular}

Total

$414 \quad 100.00$

Wirth's standard: weight for Height: ideal weight in $\mathrm{kg}=$ ht. in $\mathrm{cm} \mathrm{X} 0.4=$ wt. in $\mathrm{kg}$

Percentage of deficit or excess food standard weight $=$ Actual weight- standard weight / standard weight X 100

capita income and type of work performed. Table 7 shows that, lower educated and low income group employees form the major proportion $(58.66 \%$ and $56 \%)$ of the over nourished employees in terms of BMI. This provides some indication on lack of awareness and knowledge on food and nutrition and balance diet. Employees, under light work (sedentary) category (which is supposed to be educated and highly paid) form a low percentage of over nutrition category. The comparison of the present observation with other research studies to draw conclusion was not possible as the number of studies particularly in these aspects were very limited. But an awareness program on food and nutrition, balance diet and impact of nutrition is desirable for these categories of workers to educate them on the various aspects of food and nutrition, its effect on

Table 7: Grades of malnutrition (BMI) in relation to education, income and type of work

\begin{tabular}{|c|c|c|c|c|}
\hline & $\begin{array}{l}\text { Under nutrition } \\
\text { (74) }\end{array}$ & $\begin{array}{l}\text { Normal } \\
(365)\end{array}$ & $\begin{array}{l}\text { Over nutrition } \\
\text { (75) }\end{array}$ & Total \\
\hline \multicolumn{5}{|l|}{ Education } \\
\hline Matric or less with ITI & $40(40.05)$ & $153(57.73)$ & $44(58.67)$ & 237 \\
\hline General college edn. & $11(14.86)$ & $53(20.0)$ & $14(18.67)$ & 78 \\
\hline P.G. with other qualification & $23(31.08)$ & $59(22.27)$ & $17(22.66)$ & 99 \\
\hline \multicolumn{5}{|l|}{ Per capita Income } \\
\hline$<$ Rs.2000/m & $44(59.46)$ & $170(64.16)$ & $42(56.0)$ & 256 \\
\hline$>=$ Rs. $2000-$ Rs. 4000 & $18(24.32)$ & $57(21.50)$ & $23(30.67)$ & 98 \\
\hline$>=$ Rs. 4000 & $12(16.22)$ & $38(14.34)$ & $10(13.33)$ & 60 \\
\hline \multicolumn{5}{|l|}{ Type of Work } \\
\hline Heavy & $27(36.49)$ & $86(32.45)$ & $29(38.67)$ & 142 \\
\hline Medium & $40(54.05)$ & $149(56.23)$ & $30(40.0)$ & 219 \\
\hline Light & $7(0.09)$ & $30(11.32)$ & $16(21.33)$ & 53 \\
\hline
\end{tabular}

Figures in the parenthesis indicates percentage 
prevalence of obesity and on the problems associated with obesity.

\section{CONCLUSION}

Because of the dearth of research on the food and nutrition intake and nutritional status of the industrial workers, comparison of the present observation with other similar findings was not possible. However in view of the above results and discussion some recommendations are suggested which may be used as the tips for improving the quality of food supplied by the canteen.

The intake of pulses, roots and tubers, fats and oils should be reduced to decrease the calorific value of the diet, supplied by the canteen. Some fresh fruits, fibrous vegetables, and some raw vegetables may be included, in the diet, especially in the form of salads to provide bulk and to reduce the caloric content of the diet .The amount of fresh curd should be increased in the diet of vegetarians. Vegetables rich in Beta-carotene like carrot, papaya, different green leaves (leaves of radish, carrot, onions etc.) should be included in the diet. It is very much essential to follow the method of cooking in which the use of oil is less, i.e. boiling, steaming, stewing, sauteing, braising, roasting, grilling and as well as pressure cooking. The common practice of deep fat frying of most of the food items should be avoided. To enhance the qualities of the diet, it is essential to include different types of cereals like rice, wheat, jowar, bajra, ragi etc in the menu. Similarly different types of dals (legumes) also should be included in the menu. A menu consisting of combination of foods increases the nutritive value and adds variety to the diet. Germination and fermentation enhances the nutritive value of foods without any additional cost. Thus sprouted grains and legumes should be included in the meal, which should be eaten raw with salt and lemon juice. Fermented mixture of legumes and rice is commonly used (preparation of idli) in the canteen. Some other fermented products may be included. The sanitary and hygienic conditions of kitchens and dining area may be improved considerably as well as the personal hygiene of personnel handling the food.

Diet counseling should be imparted individually to the workers with the help of visual aids like charts, pamphlets and diet sheets on consequences of over-eating, danger of obesity, prin- ciples and methods of weight control, importance of dietary modification with special reference to energy balance, quantity and quality of fats to be used and inclusion of liberal amount of fibrous foods should be stressed. Approaches for improvement of health and nutritional status, food and nutrition knowledge of the workers are also recommended. Efforts should be taken to educate the workers on fundamentals of nutrition emphasizing role of good nutrition in improving work capacity. Mass education efforts to encourage choice of low cost nutritious foods, better health care education and discourage use of alcohol are also suggested.

\section{ACKNOWLEDGEMENTS}

The authors are thankful to Indian Aluminium Company, Hirakud Smelter, Hirakud for providing financial and logistic support to undertake the work in their premises.

\section{REFERENCES}

Banerjee S, Acharya K, Chattopadhya DP, Sen R 1959. Studies on Energy Metabolism of Labourers in a Spinning Mill. Indian Journal of Medical Research, 47: 657-662.

De Mello ER 1950. A Nutritional Survey Amongst factory Workers in Bombay Indian Journal of Medical Research, 4: 337-344.

Gopaldas T, Seshadri S 1987. Nutrition: Monitoring and Assessment. New Delhi: Oxford Univ. Press, pp. 185-187.

Gopalan C, Rarnasastri BV,Balasubramaniam SC 1991. Nutritive value of Indian Foods, (Food Composition Tables). Hyderabad: National Institute of Nutrition (ICMR).

Indian Council of Medical Research 1984. Recommended Dietary Intakes for Indians. , New Delhi: ICMR.

Jelliffe DB 1966. The Assessment of the Nutritional Status of the Community, WHO Monograph Series No.53. Geneva: World Health Organization.

Park JE, Park K 1991. Preventive and Social Medicine. Jabalpur: Benarasi Das Bhanot.

Paul Deurenberg, Strate Jan A West, Seidell Jaap C 1991. Body Mass Index as a measure of body fitness, age and sex specific formulas. British Journal of Nutrition, 65:105-114.

Ramanamurthy PSV, Dakshayani 1962. Energy Intake and Expenditure in Stone Cutters. Indian Journal of Medical Research, 50: 804-809.

RaoKV, Rao, Parvathi, Thimmayamma BVS 1986. Nutritional Anthropometry of Indian Adults. Indian Journal of Nutrition and Dietetics, 23(3): 239256.

Sarojini JK, Nayak RK, Surendra HS 1990. Nutritional Assessment of Elderly through Anthropometric Measurement in an Urban Area of Karnataka. Indian Journal of Nutrition and Dietetics, 27(1): 9194. 
Satyanarayana K, Hanumantha Rao D, Vasudeva Rao D, Swarninathan MC 1972. Nutritional and Working Efficiency in Coal Mines. Indian Journal of Medical Research, 60: 1800-1806.

Satyanarayana K, Nandamuni Naidu A, Chaterjee B, Narasinga Rao BS 1977. Body Size and Work Out put. American Journal of Clinical Nutrition, 30: 322-325.

Satyanarayana K, Narasinga Rao BS, Srikantia SG 1979. Nutrition and Work Out put. Indian Journal of Nutrition and Dietetics, 16(2): 170-174.
Sharan S, Puttaraj S 2003. Nutritional Status of women Employees of Public Sector Electronics Industry consuming Home and Canteen Food. Journal of Human Ecology, 14(1): 43-46.

Swaminathan M 1967. The Nutrition and Feeding of Industrial Workers in Developing Countries. Indian Journal of Nutrition and Dietetics, 4(1): 131152.

World Health Organization (WHO) 1978. A Decade of Health Development in South East Asia. New Delhi: WHO, South-East-Asia-Regional Office. 